\title{
A EDUCAÇÃO E O MEIO AMBIENTE NA PERSPECTIVA DA AGENDA 2030: pesquisa participante sobre coleta seletiva no ambiente escolar
}

\section{EDUCATION AND THE ENVIRONMENT IN THE PERSPECTIVE OF AGENDA 2030: participating research on selective collection in the school environment}

\author{
Dulce da Silva Reis ${ }^{1}$ \\ Luiza Moreira de Oliveira ${ }^{2}$ \\ Maria Célia da Silva Gonçalves ${ }^{3}$ \\ https://doi.org/10.29327/216986.1.1-1
}

RESUMO: O presente estudo desenvolvido por meio de uma pesquisa qualitativa, teve como escopo analisar os resultados de uma pesquisa participante realizada em uma escola periférica na cidade de João Pinheiro (MG) no que tange a inserção da coleta seletiva no espaço escolar, tendo em vista à preservação do meio ambiente, tornando um espaço gerador de sustentabilidade. A concretização do estudo se justifica pela necessidade de despertar a sensibilidade dos alunos com relação ao destino dos resíduos sólidos da escola em geral. O objetivo principal desse estudo foi desenvolver uma proposta para a conscientização dos alunos sobre a questão de descartar os resíduos que eles mesmo geram e também a comunidade, além disso, inserir a coleta seletiva na escola, ensinando a eles os tipos de materiais que devem ser descartados nas respectivas cores dos recipientes coletores, e assim mostrando-os práticas simples que eles podem começar a praticar contra o desperdício, fazendo uma grande subsídio para o

\footnotetext{
1 Licenciada em Pedagogia pela Faculdade do Noroeste de Minas-FINOM. E-mail: dulcinha93@gmail.com

2 Licenciada em Pedagogia pela Faculdade do Noroeste de Minas-FINOM. E-mail: luizamoreira02@hotmail.com

${ }^{3}$ Pós-doutorado em Educação pela Universidade Católica de Brasília (UCB). http://lattes.cnpq.br/9176266551850173 E-mail: mceliasg@yahoo.com.br
} 
cuidado com o meio ambiente, envolvendo os estudantes, os membros da comunidade, gestores, funcionários e professores e com isso desenvolvendo diálogos entre os conhecimentos locais voltados à melhoria da qualidade de vida daquela comunidade, podendo levar a ideia para frente. Os s resultados foram analisados à luz dos objetivos preconizados pela Agenda 2030 e apontam para a importância de a escola atuar efetivamente para a concretização de tais objetivos.

Palavras-chave: Agenda 2030. Sustentabilidade. Conscientização. Educação. Coleta Seletiva.

ABSTRACT: The present study, developed through a qualitative research, aimed to analyze the results of a participant research carried out in a peripheral school in the city of João Pinheiro (MG) regarding the insertion of selective collection in the school space, with a view to preservation of the environment, making it a space that generates sustainability. The completion of the study is justified by the need to awaken students' sensitivity regarding the destination of solid waste from the school in general. The main objective of this study was to develop a proposal to raise students' awareness of the issue of disposing of the waste they themselves generate and also the community, in addition to inserting selective collection at school, teaching them the types of materials that should be used. discarded in the respective colors of the collecting containers, and thus showing them simple practices that they can start to practice against waste, making a great subsidy for the care of the environment, involving students, community members, managers, employees and teachers and thereby developing dialogues between local knowledge aimed at improving the quality of life of that community, and can take the idea forward. The results were analyzed in the light of the objectives advocated by the agenda 2030 and point to the importance of the school acting effectively to achieve these objectives. 
Keywords: Agenda 2030. Sustainability. Awareness. Education. Selective collect.

\section{Introdução}

Atualmente assistimos um debate crescente sobre uma educação que promova o meio ambiente e a sustentabilidade de forma planetária e nacional. Embora esse debate não seja novo, ele adquiriu maior intensidade pós 2015, quando foi realizado um encontro que deu origem a agenda 2030. De acordo com António Guterres, Secretário Geral da ONU: "a Agenda 2030 é a nossa Declaração Global de Interdependência."

Nesse sentido é importante e salientar que,

Em setembro de 2015, representantes dos 193 Estadosmembros da ONU se reuniram em Nova York e reconheceram que a erradicação da pobreza em todas as suas formas e dimensões, incluindo a pobreza extrema, é o maior desafio global e um requisito indispensável para o desenvolvimento sustentável. Ao adotarem o documento "Transformando o Nosso Mundo: A Agenda 2030 para o Desenvolvimento Sustentável" (A/70/L.1), os países comprometeram-se a tomar medidas ousadas e transformadoras para promover $\mathrm{o}$ desenvolvimento sustentável nos próximos 15 anos sem deixar ninguém para trás. (PNUD/AGENDA 2030,2015)

Trata-se de um plano de ação para as pessoas, o planeta e a prosperidade, que busca fortalecer a paz universal. O documento indica 17 Objetivos de Desenvolvimento Sustentável, os ODS, e 169 metas, para erradicar a pobreza e promover vida digna para todos, dentro dos limites do planeta. São objetivos e metas claras, para que todos os países adotem de acordo com suas próprias prioridades e atuem no espírito de uma parceria global que orienta as escolhas necessárias para melhorar a vida das pessoas, agora e no futuro. (PNUD/AGENDA 2030,2015)

Educação In Loco, v.01, n. 01, jan.-jun. 2020 
Trabalhar com temas relevantes para a nossa sociedade é um dos passos para o desenvolvimento social, intelectual e cultural, pois, o trabalho em si envolve além de uma postura diferenciada o contato com a diversidade em que o ser humano precisa vivenciar, nesse aspecto percebemos a importância da educação, que é fundamental para que as pessoas tenham um esclarecimento sobre temas variados. A demais a educação é responsável por tornar o ser humano dono do seu entendimento e capaz de desenvolver posturas críticas diante de assuntos que sejam considerados indispensáveis para a nossa sociedade.

O relatório Nosso Futuro Comum (1987), define desenvolvimento sustentável: "O desenvolvimento que procura satisfazer as necessidades da geração atual, sem comprometer a capacidade das gerações futuras de satisfazerem as suas próprias necessidades". A educação é vista como a porta de entrada do conhecimento, ela por si só não resolve os problemas que surgem no nosso meio, porém é muito importante para as decisões corretas. Nessas decisões podemos citar a mudança de comportamentos referentes ao meio ambiente. (PNUD/AGENDA 2030, 2015)

Nesse sentido o objetivo 4- Educação de Qualidade estabelece "Assegurar a educação inclusiva e equitativa de qualidade, e promover oportunidades de aprendizagem ao longo da vida para todos." Isso se trona mais explícito na meta 4.7, que preconiza que

Até 2030, garantir que todos os alunos adquiram conhecimentos e habilidades necessárias para promover o desenvolvimento sustentável, inclusive, entre outros, por meio da educação para o desenvolvimento sustentável e estilos de vida sustentáveis, direitos humanos, igualdade de gênero, promoção de uma cultura de paz e não-violência, cidadania global, e valorização da diversidade cultural e da contribuição da cultura para o desenvolvimento sustentável. (PNUD/AGENDA 2030, 2015)

Educação In Loco, v.01, n. 01, jan.-jun. 2020 
As mudanças de comportamentos deveriam fazer parte da vida dos seres humanos, para que cuidar do meio ambiente comece a acontecer com mais consciência no ambiente escolar através de ações de educadores. Mostrar aos educandos como é importante a preservação do mesmo tem sido fator fundamental nos últimos anos, isto porque estamos vivendo em épocas de grandes desastres ambientais.

Antes de partir para uma discussão sobre a Educação Ambiental devemos falar um pouco sobre sustentabilidade e a sua importância para que tenhamos uma conscientização em relação ao meio ambiente. Ao trabalharmos a sustentabilidade na escola estamos fazendo com que as gerações futuras tenham a consciência e responsabilidade de fazer as tomadas de decisões no futuro, pois sabemos que essas crianças de hoje é que serão os futuros governantes, empresários e quem sabe os políticos de amanhã.

A agenda 2030 em sua meta 2.4 do objetivo 2 preconiza que:

Até 2030, garantir sistemas sustentáveis de produção de alimentos e implementar práticas agrícolas robustas, que aumentem a produtividade e a produção, que ajudem a manter os ecossistemas, que fortaleçam a capacidade de adaptação às mudanças do clima, às condições meteorológicas extremas, secas, inundações e outros desastres, e que melhorem progressivamente a qualidade da terra e do solo. (PNUD/AGENDA 2030, 2015)

$\mathrm{O}$ assunto sustentabilidade na educação é um projeto que deve ser tratado de forma ininterrupta, seja com ações simples como projetos de coleta seletiva até mesmo a implantação de programas mais criteriosos pelos professores em parceria com órgãos públicos.

No entanto devemos salientar que o desenvolvimento sustentável:

[...] procura satisfazer as necessidades da geração atual, sem comprometer a capacidade das gerações futuras de satisfazerem as suas próprias necessidades, significa possibilitar que as pessoas, agora e no futuro, atinjam

Educação In Loco, v.01, n. 01, jan.-jun. 2020 
um nível satisfatório de desenvolvimento social e econômico e de realização humana e cultural, fazendo, ao mesmo tempo, um uso razoável dos recursos da terra e preservando as espécies e os habitats naturais" (Relatório Brundtland). Educação para o desenvolvimento sustentável: é um "conceito dinâmico que compreende uma nova visão da educação que busca empoderar pessoas de todas as idades para assumir a responsabilidade de criar e desfrutar um futuro sustentável. (UNESCO, 2002).

O projeto desenvolvido na escola deve chegar até as casas dos nossos alunos, pois é preciso que se alinhe na família o que aprendemos no ambiente escolar. Ações pequenas e simples como separar os resíduos que produzem na sua própria casa é um passo para a continuação do trabalho de sustentabilidade desenvolvido na escola.

Para Gadotti (1995, p. 83), “a força da educação está no seu poder de mudar comportamentos. Mudar comportamentos significa romper com certas posturas, superar dogmas, desinstalar-se, contradizer-se". Nessa perspectiva, a escola tem a função de alfabetizar os indivíduos cientificamente para que possam exercer seu papel como sujeito e cidadão.

A coleta seletiva minimiza o desperdício de matéria prima, separando corretamente os resíduos e destinando os mesmo para sua constituição ou decomposição adequada. Foi implantado esse projeto para a finalidade de possíveis mudanças e atitudes dos alunos no meio ambiental.

Justifica-se este estudo por entendermos que ao ensinar os alunos sobre a importância do desenvolvimento de hábitos sustentáveis como coleta seletiva e separação dos resíduos que são produzidos por eles no ambiente escolar e posteriormente a utilização dessa prática em suas casas é bastante relevante para a educação escolar ambiental, pois devemos ter em mente que um ambiente saudável do ponto de vista da coleta seletiva é bom não somente para os alunos e sim para toda a escola e comunidade escolar; é fazer a teoria virar de fato prática constante.

Educação In Loco, v.01, n. 01, jan.-jun. 2020 
O objetivo principal deste estudo foi desenvolver uma proposta para a conscientização dos alunos sobre a questão de descartar os resíduos que eles mesmo geram e também a comunidade, além disso, inserir a coleta seletiva na escola, ensinando a eles os tipos de materiais que devem ser descartados nas respectivas cores dos recipientes coletores, e assim mostrando-os práticas simples que eles podem começar a praticar contra o desperdício, fazendo uma grande subsídio para o cuidado com o meio ambiente, envolvendo os estudantes, os membros da comunidade, gestores, funcionários e professores e com isso desenvolvendo diálogos entre os conhecimentos locais voltados à melhoria da qualidade de vida daquela comunidade, podendo levar a ideia para frente.

Foi utilizado a seguinte metodologia para a execução deste trabalho: através de pesquisa bibliográfica e de campo onde foi aplicado práticas de preservação através de jogo didático-pedagógico com o intuito de fazer com que os alunos aprendam a fazer a coleta seletiva através das cores, para isso foi contado com a participação da professora regente de uma escola pública e a alguns alunos para mostrar a importância de conservar o espaço em que eles estão. A relevância social dessa pesquisa é a conscientização dos alunos, e a acadêmica é mostrar o quanto professores podem contribuir de forma significativa e simples para ensinar os alunos à consciência de estar em um ambiente sustentavelmente correto. Essa consciência ambiental deve inserir quando os alunos ainda estão iniciando os estudos, pois assim quando crescerem terá internalizado dentro deles essa consciência de preservação.

Com este estudo não se pretende esgotar o objetivo de pesquisa, mas, deixamos evidenciado que o mesmo é passível de novas interpretações sob olhar e interesse de outros pesquisadores.

\section{Objetivos}

Desenvolver uma proposta para a conscientização dos alunos em uma escola em um bairro de periferia, localizada no município de João Pinheiro - MG, sobre a questão dos resíduos sólidos, mostrando 
a eles um meio de defender e cuidar do meio ambiente; implantar a coleta seletiva, ensinando aos alunos os tipos de materiais a serem depositados nas respectivas lixeiras identificadas por cores; evidenciar como as práticas simples do dia a dia pode engrandecer a conservação do meio ambiente, desenvolvendo práticas sustentáveis e duradouras; instrumentalizar os alunos para que ele possam se tornar pessoas melhores capazes de lutar por um planeta saudável e de todos.

\section{Metodologia}

O presente trabalho foi realizado na modalidade de pesquisa qualitativa; entendemos que a "abordagem qualitativa, enquanto exercício de pesquisa, não se apresenta como uma proposta rigidamente estruturada, ela permite que a imaginação e a criatividade levem os investigadores a propor trabalhos que explorem novos enfoques". (GODOY, 1995, p.20)

A coleta de dados se efetivou por meio de uma pesquisa participante, por entendermos que:

A pesquisa participante pode ser aloca da dentro do espaço da pesquisa prática, como corrente especifica, embora prefiramos colocar ambas como sinônimas. A pesquisa participante busca a identificação totalizante entre sujeito e objeto, de tal sorte a eliminar a característica de objeto. A população pesquisa é motivada a participar da pesquisa como agente ativo, produzindo conhecimento, e intervindo na realidade própria. A pesquisa torna-se instrumento no sentido de possibilitar à comunidade assumir seu próprio destino. Ao pesquisador que vem de fora cabe identificar-se ideologicamente com a comunidade, as sumindo sua proposta política, a serviço da qual se coloca a pesquisa. (DEMO, 1982, p.27)

O trabalho foi desenvolvido na cidade de João Pinheiro- MG, em uma escola municipal, situada e um bairro de periferia da cidade. O público participante de uma pesquisa desenvolvida e uma palestra realizada foram os alunos em geral que estudam no turno vespertino,

Educação In Loco, v.01, n. 01, jan.-jun. 2020 
os professores e os demais funcionários da escola, onde a confecção do projeto e as brincadeiras foram feitas com os alunos do maternal II.

Para iniciar o trabalho foi feito uma visita à escola para saber mais sobre como se tratava o assunto de educação ambiental naquele meio, como os alunos eram incentivados, e se o que estava sendo ensinado era feito em prática.

Em seguida uma pequena pesquisa foi feita com os alunos que estavam presentes na escola e também com os funcionários que estavam trabalhando naquele turno, desde professores, cantineira, secretárias e o guarda da escola, onde era questionado o entendimento sobre coleta seletiva e se conheciam sobre o assunto ou desconhecia do mesmo, por se tratar de um tema transversal e não muito trabalhado na cidade.

Foi realizada uma palestra, onde foi falado sobre a importância de descartar o lixo no local correto, mostrando os malefícios que pode acarretar para o bem-estar da população e para o meio ambiente, relacionando a importância da Educação Ambiental. Para a realização da palestra, foi mostrado também vídeos educativos e cartazes elaborados pelos alunos, com o objetivo de esclarecer as dúvidas que foram feitas na pesquisa, mostrando a todos o quanto fazermos a seleção dos resíduos gerados é de grande relevância para conservar o meio ambiente.

Posterior a palestra outra atividade foi desenvolvida com os alunos do maternal II, nesse momento foi escolhido essa turma a ser trabalhado o projeto com o intuito de que a educação infantil é o princípio da vida escolar de todos os alunos, e é onde eles aprendem deveres e valores, no qual carregam consigo pela vida toda, nessa idade as crianças são curiosas e a partir daí desenvolvem a capacidade de observar estando sempre dispostas a aprender mais.

Um jogo foi adaptado a sala de aula, onde os alunos deveriam escolher um objeto dentro de uma caixa surpresa e descartá-lo na lixeira correta, para ser feito a Coleta Seletiva, após a brincadeira, os alunos juntamente com as idealizadoras do projeto e a professora regente da sala de aula foram para o pátio onde haviam sido instaladas as lixeiras com as cores que identificavam os resíduos aonde eles

Educação In Loco, v.01, n. 01, jan.jun. 2020 
deveriam descartá-los. Foram desenvolvidos também vários jogos com litros descartáveis, e tampinhas de garrafas, visando à reciclagem e o aprender daqueles alunos.

\section{Resultados e discussões}

Após a visita e o levantamento dos saberes dos funcionários e alunos sobre Coleta Seletiva na escola municipal situada em João Pinheiro-MG foi possível traçar o perfil de conhecimento dos participantes da pesquisa sobre o assunto. (Figura 01).

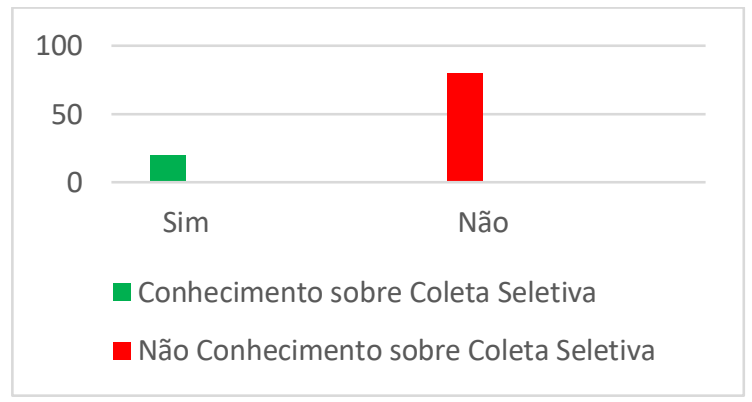

Figura 01: Conhecimento da Coleta seletiva. Fonte: As autoras - 2019

Podemos analisar através do gráfico com as pessoas pesquisadas que $20 \%$ delas conheciam o assunto e $80 \%$ não tinham conhecimento. A pesquisa foi feita com alguns funcionários e também com a participação dos alunos.

Para que a escola permaneça na jornada de transformação pedagógica o mais importante é que o conceito não seja isolado, e sim reproduzir os discursos da sociedade, transcendendo esse contexto, sendo um espaço gerador de sustentabilidade, onde ideias individualizadas desenvolve práticas sustentáveis e duradouras, além disso a mudança de valores daquela comunidade, tornando pessoas melhores capazes de lutar por um planeta saudável e de todos. 


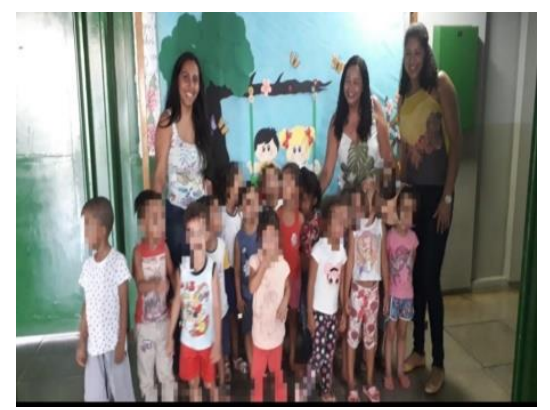

Figura 02: Momento de palestra

Fonte: As autoras - 2019

De acordo com a figura 02 notamos que foi desenvolvida uma pequena palestra com os funcionários da referida escola e também com os alunos do Maternal, a fim de que fosse feita a conscientização deles a respeito da coleta seletiva. A palestra contou com a participação dos alunos, e priorizamos o fato da sensibilização de todos os segmentos envolvidos neste projeto.

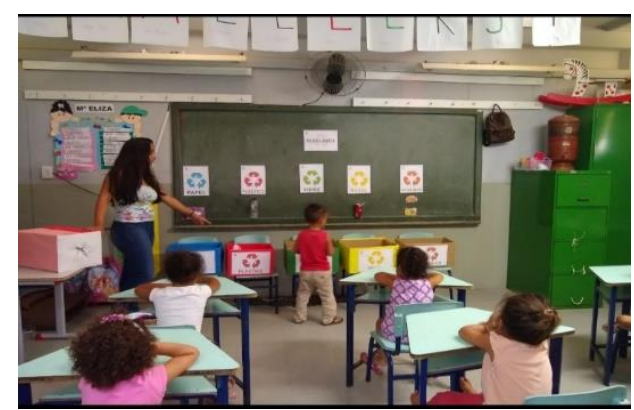

Figura 04: Depositando na lixeira correta Fonte: As autoras - 2019 


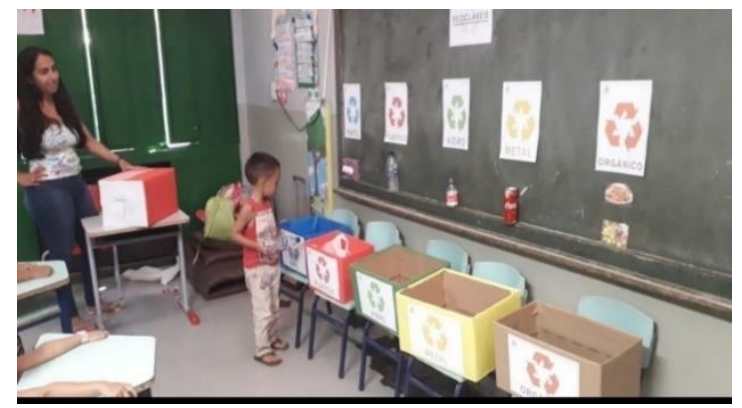

Figura: 05 Aprendendo brincando

Fonte: As autoras - 2019

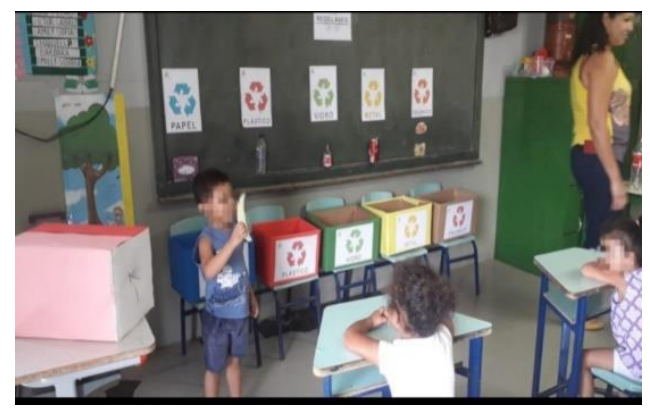

Figura 06: Lixo orgânico

Fonte: As autoras - 2019

Nas imagens das figuras 04 a 06 foi feito o momento de aprendizagem que foi desenvolvida na palestra com os alunos do Maternal, lá eles puderam colocar em prática tudo o que aprenderam na palestra, separando os resíduos através da coleta seletiva, onde foi confeccionado lixeiras de papelão com as respectivas cores corretas, onde a caixa azul depositava papel, vermelha plástico, verde vidros, amarela metal e a marrom os orgânicos. 


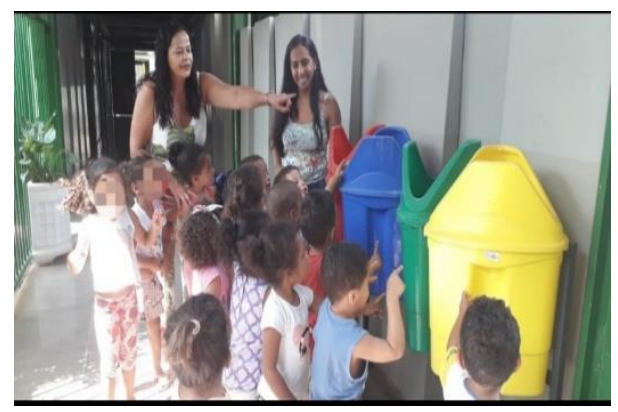

Figura 07: Lixeiras coletoras

Fonte: As autoras - 2019

$\mathrm{Na}$ figura 07 os alunos juntamente com as idealizadoras do projeto e a professora regente da sala de aula foram para o pátio onde haviam sido instaladas as lixeiras com as cores que identificavam os resíduos aonde eles deveriam descartá-los.

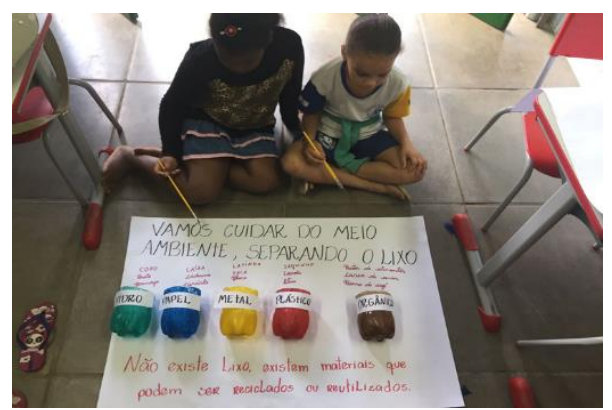

Figura 08: Confecção de cartazes

Fonte: As autoras - 2019

Um dos trabalhos desenvolvidos pelas acadêmicas que foi de suma importância em relação ao tema foi à confecção de cartazes, que logo que ficou pronto foi colado na sala para não deixar os alunos esquecerem aonde deve ser depositado o lixo produzido por eles após as atividades em sala de aula. (Figura 08). 


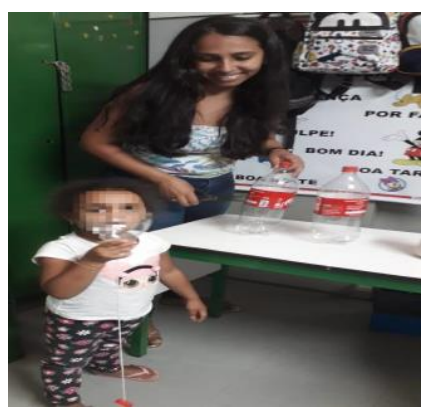

Figura 09: Confecção de brinquedos

Fonte: As autoras - 2019

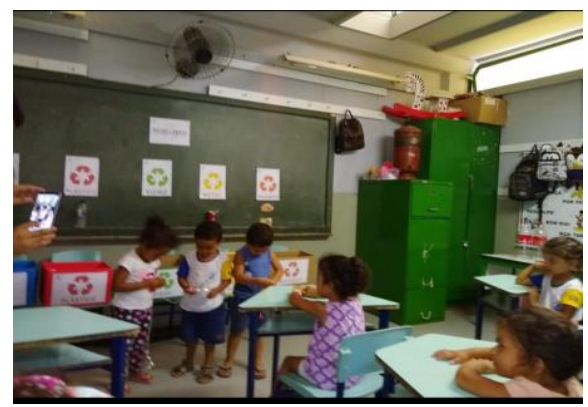

Figura 10: Diversão garantida

Fonte: As autoras - 2019

Nas figuras 09 e 10 as pesquisadoras confeccionaram vários brinquedos com os alunos e todos se divertiram bastante confeccionando e também brincando com os jogos feitos por eles mesmos.

Desenvolver um tema pouco trabalhado no contexto escolar e também inovador é muito desafiador e ao mesmo tempo contagiante, onde ver a evolução do aluno preocupado em depositar o seu resíduo no local adequado, e consciente que esse ato é para o bem-estar de todos. Propõe-se que a Educação Ambiental, não seja somente um tema transversal, e passe a ser uma disciplina avulsa, assim, dando uma importância maior a esse conteúdo, sendo um fator primário no cenário educacional, andando juntas com as outras disciplinas.

Educação In Loco, v.01, n. 01, jan.-jun. 2020 
Tendo em vista que a educação por si só, muitas vezes não é capaz de dar as respostas a todos os anseios e necessidades de toda uma sociedade, principalmente porque o estímulo a competitividade irracional de muitos, é totalmente pertinente a colocação de LOUREIRO (1999) que idealiza a Educação ambiental como “(...) um processo educativo de construção da cidadania plena e planetária, que visa a qualidade de vida dos envolvidos e a consolidação de uma ética ecológica".

Quando os indivíduos são analisados como um todo nota-se que os alunos aprendem e ensinam, separando; porém isso não é aproveitado quando se fala em seletividade dos resíduos que nós mesmos produzimos. O ambiente em que se vive hoje é tratado como descarte, isso tudo que é descartado é uma coisa que não serve mais, e não é pensado que esse resíduo pode ser reaproveitado por outros, assim a limpeza do ambiente acontece, gerando ainda empregos e uma outra forma de vida para essas pessoas.

A produção de resíduos pelas pessoas está sendo cada vez maior, visto que a população cresceu bastante nas últimas décadas, e essa preocupação em onde descartar o que produzimos deveria ser uma questão de prioridade por todos nós. Os resíduos que produzimos devem ter um destino final onde não impacta o meio ambiente de forma significativa.

A reciclagem é processo que interessa ao meio ambiente, constituindo em instrumento eficaz para a preservação dos recursos naturais, pois implica a reintrodução dos materiais no processo produtivo, reduzindo o desgaste físico do meio (MARQUES, 2005, p. 122).

A realidade da Educação Ambiental no espaço escolar requer do professor uma postura diferenciada, não querendo este ser o "dono do saber", a questão é instigar o aluno a pensar como a preservação do meio ambiente é importante não somente para a atual população como também para as próximas gerações, com isso devemos pensar: o que podemos deixar para os nossos sucessores? Esta é uma questão a ser analisada e como resposta deixar os alunos fazerem essa reflexão ambiental.

Educação In Loco, v.01, n. 01, jan.-jun. 2020 


\section{Considerações finais}

$\mathrm{Na}$ atualidade, a maioria da população brasileira vive em cidades, com esse fator ressalta-se uma condição de vida ruim, devido à poluição de indústrias, carros, entre vários fatores, refletindo uma crise ambiental. Tudo isso demanda uma séria preocupação e desafios para tentar mudar o jeito de pensar e agir das pessoas, em uma perspectiva moderna, é dificultoso implantar meios de mudança radical como o comportamento da população, onde o aspecto econômico e o desenvolvimento são visados de uma forma primordial.

Segundo os Parâmetros Curriculares Nacionais (BRASIL, 1998), para administrar a problemática do lixo é necessária uma combinação de métodos, que vão da redução, dos rejeitos, durante a produção até as soluções técnicas de destinação, como a reciclagem, a compostagem, o uso de depósitos e os incineradores.

Com a realização deste trabalho concluímos que a Educação Ambiental é importante ser trabalhada de forma a fazer o aluno compreender que o planeta e o meio em que se vivem necessitam ser respeitado, e com isso o trabalho com os alunos menores torna-se dignificante, uma vez que quando educamos para o meio ambiente eles absorvem bem e praticam. Isso de fato é visto com um olhar mais apurado pelos que estão envolvidos nesse processo de ensino aprendizagem.

Fazer a sensibilização dos alunos tornou-nos seres capazes de apreender o quanto a Educação Ambiental através do trabalho com a coleta seletiva faz com que a contribuição enquanto educadoras é importante para um ambiente corretamente modificado. É preciso que a escola demonstre em seu projeto educativo que aquilo que a criança presencia fora da sala de aula também influencia na sua educação. As relações interpessoais nas famílias e comunidades, a forma como os adultos tratam as crianças, a forma de lidar com a limpeza ou com o lixo, entre outros, representam situações de ensino e aprendizagem (TRINDADE, 2011). 
Pelo exposto neste trabalho, pode-se perceber que para acontecer um programa ambiental, é preciso que o maior número de pessoas da sociedade participe em favor de um objeto comum, sendo de suma importância a participação dos integrantes da instituição, engajando-se nos esforços do desenvolvimento de ações de educação ambiental, envolvendo todos para um resultado contagiante, promovendo discussões e a construção de conceitos de forma coletiva, tentando resolver o problema, visto que preservar é preciso.

Portanto, o caminho para que os indivíduos sejam conscientizados e para que isso se multiplique nessa geração do presente e passe para as futuras, se faz essencial desenvolver a educação ambiental no interior e exterior escola, desenvolvendo projetos que envolvam os alunos em sala de aula, tornando idealizadores de maneiras sustentáveis, no cenário do meio ambiente.

\section{Referências bibliográficas}

BRASIL. Secretaria da Educação. Parâmetros Curriculares Nacionais: terceiro e quarto

ciclos - apresentação dos temas transversais. Secretaria da Educação Fundamental.

Brasília: MEC/SEF, 1998.

DEMO, Pedro. Pesquisa participante: Mito e realidade. Brasília: UnB/Inep: 1982.

GODOY, Arilda Schmidt. Introdução à pesquisa qualitativa e suas possibilidades. RAE-Revista de Administração de Empresas, São Paulo, v. 35, n. 2, p. 57-63, 1995.

GADOTTI, M. Pedagogia da práxis. São Paulo: Cortez, 1995

LOUREIRO, C. F. B. Considerações sobre o conceito de Educação Ambiental. Revista Teoria e Prática da Educação. Maringá, PR, v.2, n.3, 1999.

MARQUES, J. R. Meio Ambiente Urbano. Rio de Janeiro: Forense Universitária, 2005

PROGRAMA DAS NAÇÕES UNIDAS PARA O DESENVOLVIMENTO (PNUD). Acompanhando a agenda 2030

Educação In Loco, v.01, n. 01, jan.-jun. 2020 
para o desenvolvimento sustentável: subsídios iniciais do Sistema das Nações Unidas no Brasil sobre a identificação de indicadores nacionais referentes aos objetivos de desenvolvimento sustentável/Programa das Nações Unidas para o Desenvolvimento. Brasília: PNUD, 2015. 250 p.

TRINDADE, NAD. Consciência Ambiental: Coleta seletiva e reciclagem no ambiente. Enciclopédia Biosfera, Centro Científico Conhecer - Goiânia, vol.7, N.12; 2011

UNESCO, Education for Sustainability - from Rio to Johannesburg:

Lessons Learnt from a Decade of Commitment, 2002 